\title{
Ultrafiltration-Based extraction of Ibuprofen from human plasma samples and HPLC analysis: developing an innovative bioanalytical analysis method
}

\author{
Yasin SENOL ${ }^{1}$ (D), Aysegul DOGAN ${ }^{1, *(D)}$, Mustafa ÇELEBIER ${ }^{1}$ (D) \\ ${ }^{1}$ Hacettepe University, Faculty of Pharmacy, Department of Analytical Chemistry, Ankara/ TURKEY
}

\begin{abstract}
Some commercially available scientific products for ultrafiltration are readily available and have been used for a long time, especially in environmental sciences, life sciences and analysis of active ingredients from plants. Recent studies of metabolomics discuss the advantage and disadvantage of ultrafiltration versus protein precipitation and solid phase extraction. However, ultrafiltration techniques are rarely used in pharmaceutical analysis, even though they have advantages over solid phase extraction, such as easy to apply and no buffer preparations. The aim of this study is to develop a simple and innovative analysis technique for IBU determination from human plasma samples by ultrafiltration-based extraction in a pharmaceutical analysis. the prepared samples were analyzed using HPLC system equipped with C18 Column ( $100 \times 4.6 \mathrm{~mm}, 3.5 \mu \mathrm{m})$. The flow rate was set to $1.0 \mathrm{~mL} \mathrm{~min}^{-1}$ while using isocratic elution with the mobile phase of [acetonitrile: phosphate buffer $(\mathrm{pH} 3.0,15 \mathrm{mM})$ $(56: 44 \mathrm{v} / \mathrm{v})]$ solution. Injection volume was $20 \mu \mathrm{L}$ and $\mathrm{UV}$ detection was performed at $220 \mathrm{~nm}$ wavelenght. The developed method was validated according to FDA Bioanalytical Guidelines and found accurate, precise, sensitive, selective and efficient with the high recovery values samples.
\end{abstract}

\author{
Article info \\ History: \\ Received:12.12.2020 \\ Accepted:17.04.2021 \\ Keywords: \\ Ibuprofen, \\ Ultrafiltration, \\ HPLC bioanalytical \\ analysis, \\ Sample preparation.
}

\section{Introduction}

Nonsteroidal anti-inflammatory drugs (NSAIDs) are known with their analgesic, anti-inflammatory and antipyretic properties [1]. NSAIDs are effective within the acute treatment of pain, as well as headache, dysmenorrhea and surgical pain [2]. The effect of NSAIDs in cancer treatment or prevention are attracting attention recently [3-7]. In a significant study conducted, it was shown that ibuprofen (IBU) is effectively used for the treatment of chronic cancer pain and provides a rise in physiological state in conjuction with a decrease within the use of narcotics in the treatment [8]. Although NSAIDs have restricted use because of their emerging side effects, they have been studied for an extended time within the pharmacological treatment of cancer pain [9-12]. Pharmacodynamic and pharmacokinetic interactions associated with the employement of NSAIDs are still under investigation [2-4]. Although it has a bright profile in terms of safety and efficacy, Ibuprofen also has potential side effects such as acute renal dysfunction, allergic reactions, gastrointestinal bleeding, and inhibition of platelet aggregation. [13]. In the light of all this data, it can be concluded that the pharmacokinetic and pharmacodynamic profiles of NSAIDs will be the subject of research for a long time.

Ibuprofen is referred as a 2 arylpropionic acid (2-APA) catagory non-steroidal anti-inflammatory (NSAID) drug [14]. Its chemical structure is shown in Figure 1. The solubility and dissolution rate of their enantiomers and their racemate are highly dependent on the temperature and $\mathrm{pH}$ of the solvent $[14,15]$. Ibuprofen is often used for the treatment of rheumatoid arthritis, osteoarthritis, pain, and fever. According to its pharmaceutical formulation, ibuprofen is absorbed from the gastrointestinal tract (GI) in about 1-2 hours [14]. Absorption is rapid and complete when given orally. The drug is highly concentrated to plasma albumin [16]. 
<smiles>CC(C)Cc1ccc([C@@H](C)C(=O)O)cc1</smiles>

(S)(+)-Ibuprofen<smiles>CC(C)Cc1ccc([C@@H](C)C(=O)O)cc1</smiles>

(R)(-)-Ibuprofen

Figure 1. Chemical structure of the R (-) and S (-) enantiometers of ibuprofen [3].

Of all the biofluids (blood, urine, saliva, sweat), whole blood is the richest in information as well as the most complex sample matrix. Blood contains $\sim 55 \%$ aqueous fraction (plasma) and $\sim 45 \%$ solids. Although blood is the primary sample in most clinical chemistrybased research, it is first converted into plasma or serum due to the lack of current sample preparation technology that can directly process whole blood [17].

There is an analytical method in the literature based on high performance liquid chromatography (HPLC) linked to a micro-extraction packed sorbent (MEPS) and photodiode array (PDA) detector to simultaneously measure multiple nonsteroidal antiinflammatory drugs (NSAIDs) and fluoroquinolones (FLQs). It is emphasized that this method may be a suitable tool to simultaneously detect a possible drug association in human biological samples [18].

Ultrafiltration is a selective separation process where membranes with 1-100 $\mathrm{nm}$ pore size are used for extracting macromolecules such as proteins. There are many factors influencing this technique like solute size, membrane pore size, the aim of the separation, and instrumental configurations. This technique is used in many areas like pharmaceutical analyses in micromolar quantity and wastewater treatment plants in micromolar quantity. These membranes also found applications in food and biotechnology. However, ultrafiltration techniques have not been used very often in pharmaceutical analysis, even though they are more advantageous over solid phase extraction, such as easy to apply and no buffer preparations [19]. The aim of this study is to develop and validate a simple and innovative analysis technique for IBU determination from human plasma samples by ultrafiltration-based extraction in a pharmaceutical analysis.

\section{Materials and Methods}

\subsection{Apparatus}

LC system Shimadzu HPLC was utilized for the analysis. Cold trap $\left(-105{ }^{\circ} \mathrm{C}\right)$ equipped CentriVap centrifugal vacuum concentrator was purchased from Labconco, USA. Hermle Z 233 M-2 (Hermle, Germany) centrifugator and Ika Vortex Genius (Germany) were used in sample preparation. Microcon $\AA$ centrifuge filters $(500 \mu \mathrm{L},<3 \mathrm{kD})$ for ultrafiltration were purchased from EMD Millipore (Darmstadt, Germany).

\subsection{Chemicals}

IBU standard solution was obtained from Gen Ilac's INTRAFEN (100 $\mathrm{mg} \mathrm{mL}^{-1}$ ) preparation. Naproxen sodium (NS, purity> 98\%) internal standard solution (was obtained from Sigma-Aldrich (St Louis, USA). Acetonitrile and methanol of analytical grade and potassium phosphate dibasic were purchased from Merck (Darmstadt, Germany). All solutions were prepared using ultra pure water produced with the Barnstead Nanopure TM (Thermo Scientific).

\subsection{Preparing mobile phase buffer of HPLC analysis}

$2.61 \mathrm{~g}$ of potassium dihydrogenphosphate $\left(\mathrm{KH}_{2} \mathrm{PO}_{4}\right)$ was dissolved in $1000 \mathrm{~mL}$ water to prepare $15.0 \mathrm{mM}$ phosphate buffer and the $\mathrm{pH}$ set to 3.0 using ophosphoric acid.

\subsection{Chromatographic conditions}

Waters XSELECT HSS C18 column (100 x $4.6 \mathrm{~mm}$, $3.5 \mu \mathrm{m}$ ) was used for separation. The flow rate was set to $1.0 \mathrm{~mL} \mathrm{~min} \mathrm{~m}^{-1}$ in isocratic elution mode using acetonitrile: phosphate buffer $(\mathrm{pH} 3.0,15 \mathrm{mM})(56: 44$ $\mathrm{v} / \mathrm{v})$ as the mobile phase. $20 \mu \mathrm{L}$ of injection volume was set and the analysis were recorded $220 \mathrm{~nm}$ wavelength.

\subsection{Ultrafiltration procedure}

The following steps were applied for sample preparation with ultrafiltration process: 
1) Plasma samples $(250 \mu \mathrm{L})$ were added into eppendorf tubes $(1.5 \mathrm{~mL})$ with methanol $(1000 \mu \mathrm{L})$ to precipitate the proteins.

2) Tubes of first stage vortexed for 30 seconds and then centrifuged at 15,000 rpm for 10 minutes.

3) $500 \mu \mathrm{L}$ of supernatants were put into ultrafiltration centrifuge tubes and centrifuged at 15,000 rpm for 1 hour.
4) $250 \mu \mathrm{L}$ of the filtrate under the filter was taken into eppendorf tubes $(1.5 \mathrm{~mL})$ and centrifuged in vacuum at $24^{\circ} \mathrm{C}$ for 24 hours.

5) $250 \mu \mathrm{L}$ of mobile phase was added to each tube and the tubes were vortexed for 30 seconds and the supernatants transferred to HPLC bottles.

The ultrafiltration procedure is presented in Figure 2.

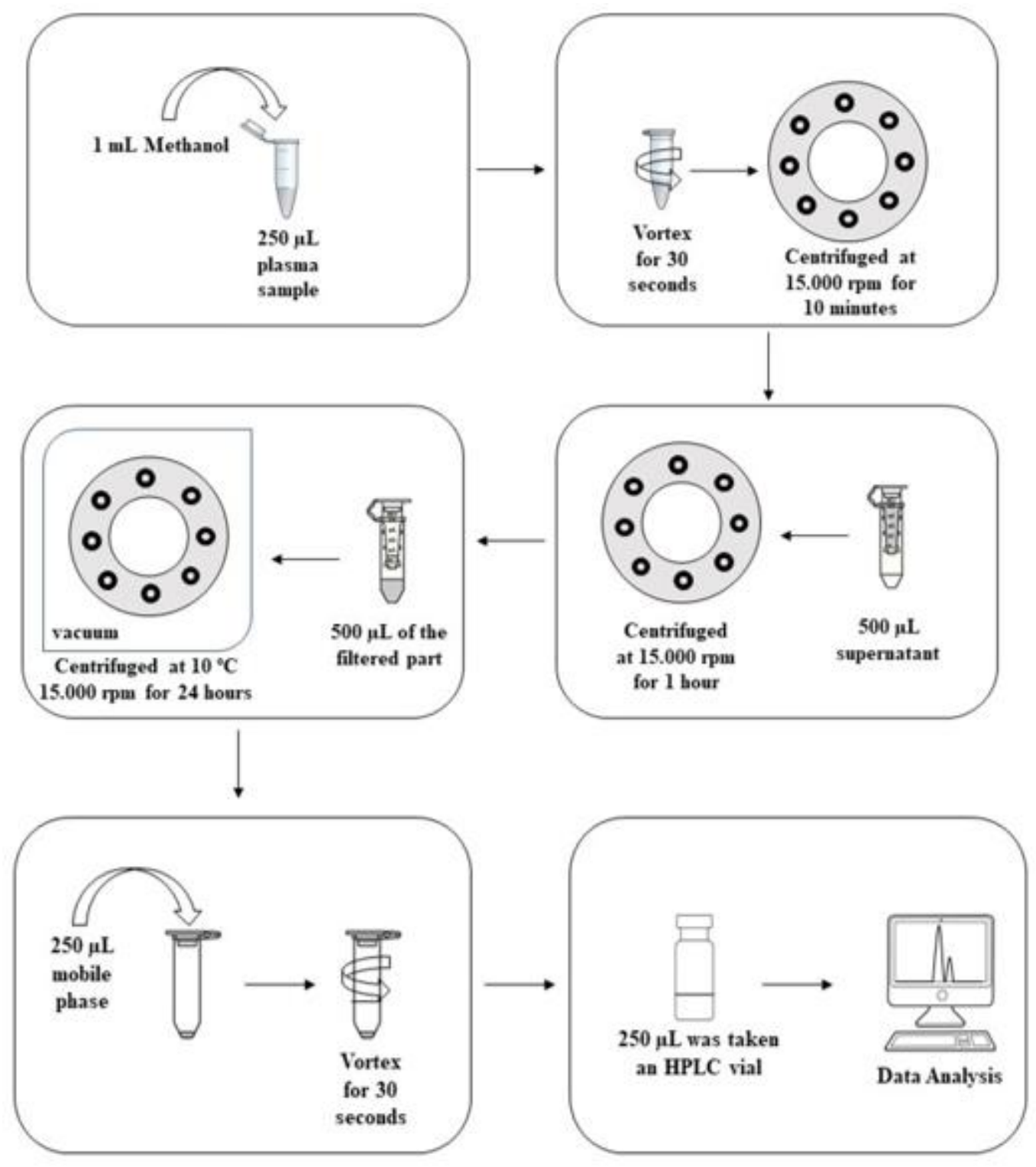

Figure 2. Schematic presentation of ultrafiltration procedure

\subsection{Standard stock solutions}

IBU (2000 $\left.\mu \mathrm{g} \mathrm{mL}^{-1}\right)$ standard stock solutions and NS $\left(1000 \mu \mathrm{g} \mathrm{mL}^{-1}\right)$ were prepared in Milli-Q water. Both of these standard solutions were kept in $4^{\circ} \mathrm{C}$ during the analysis and freshly prepared twice in a week. Appropriate dilution was applied by using micropipettes to prepare calibration standards and sample solutions.

\subsection{Calibration curve construction}

Calibration curve solutions were prepared with ultrafiltration procedure using spiked plasma samples. 
IBU standard stock solution was diluted to 2, 20 and $160 \mu \mathrm{g} \mathrm{mL}^{-1}$. NS standard stock solution was diluted to $25 \mu \mathrm{g} \mathrm{mL}^{-1}$. These solutions were put into the HPLC vials containing extracted blank plasma samples to prepare the standard solutions including $0.25,0.5,1.0$, 2.0, 4.0, 16.0, 32.0, $64.0 \mu \mathrm{g} \mathrm{mL}^{-1} \mathrm{IBU}$ and $4 \mu \mathrm{g} \mathrm{mL}^{-1}$ $\mathrm{NS}$ as an internal standard. The final volume was added upto $250 \mu \mathrm{L}$ by the mobile phase. The injected plasma standarts peak areas of IBU to NS ratios were used in construction of calibration curve against concentration.

\subsection{Recovery studies}

Samples were prepared triplicate in concentrations of 4.0, 16.0 and $64.0 \mu \mathrm{g} \mathrm{mL}^{-1} \mathrm{IBU}$ and $4 \mu \mathrm{g} \mathrm{mL}^{-1} \mathrm{NS}$ as internal standard in plasma. The mobile phase was added to fill the final volume to $250 \mu \mathrm{L}$ after the ultrafiltration procedure. The triple-replicate peak area ratio results for this group were compared on each concentration level.

\subsection{Preparation of IBU spiked plasma samples}

Plasma samples containing $20.00 \mu \mathrm{g} \mathrm{mL}^{-1}$ IBU and 4 $\mu \mathrm{g} \mathrm{mL}^{-1} \mathrm{NS}$ were subjected to ultrafiltration. The spiked samples $(\mathrm{n}=6)$ were analyzed by the calibration equation and the results were statistically evaluated by MS Excel.

\subsection{Analytical method validation}

Validation of the developed method was performed based on the FDA guidelines in terms of sensitivity, precision, trueness and selectivity [20].

\section{Results and Discussion}

\subsection{Method optimization}

According to previous studies and some experiments $[18,21-23]$, it was agreed to use acetonitrile-potassium phosphate buffer (pH: 3.0) and its mixture (56:44, v/v) as the mobile phase. A C18 column [Waters XSELECT HSS C18 $(100 \times 4.6 \mathrm{~mm}, 3.5 \mu \mathrm{m})$, PN: 186004767 SN: 01113431413401] was used for analysis. The water-soluble plasma interference was found to be quickly decomposed by dead volume, and then IBU was separated from the baseline under specified experimental conditions.

Table 1. System suitability parameters of IBU for the proposed method $(n=6)$

\begin{tabular}{lll}
\hline & Found & Requirements \\
\hline Injection repeatability (RSD of IBUt $\left.\mathrm{r}_{\mathrm{r}}\right)$ & $0.9 \%$ & $<1 \%$ \\
Capacity factor $\left(\mathrm{k}^{\prime}\right)$ & 4.73 & $>2$ \\
Efficiency $(\mathrm{N})$ & 7851 & $>2000$ \\
Tailing Factor & 1.06 & $<2$ \\
Resolution & 4.75 & $>1.5$ \\
\hline
\end{tabular}

Mobile phase optimisation ended up with acetonitrile: potassium phosphate buffer ( $\mathrm{pH} 3.0,15 \mathrm{mM})(56: 44$, $\mathrm{v} / \mathrm{v})$. It was observed that run time of the analysis was less than 10.0 minutes. Chromatograms of calibration standards, blank, added sample and standard solutions are given in Figure 3. The calibration standards prepared in the mobile phase and stored at ambient temperature $\left(24-28{ }^{\circ} \mathrm{C}\right)$. These solutions were then injected 24 hours later to check the stability.
There was no difference observed between the peak areas compared to previous injections. This process was applied three times for $20.0 \mu \mathrm{g} \mathrm{mL}-1$ IBU calibration standard. The system compatibility and injection stability of the developed HPLC method thus proved. The system suitability of method meets the requirements and the prepared solutions can be injected within 24 hours when they are kept in the automatic sampler (Table 1). 


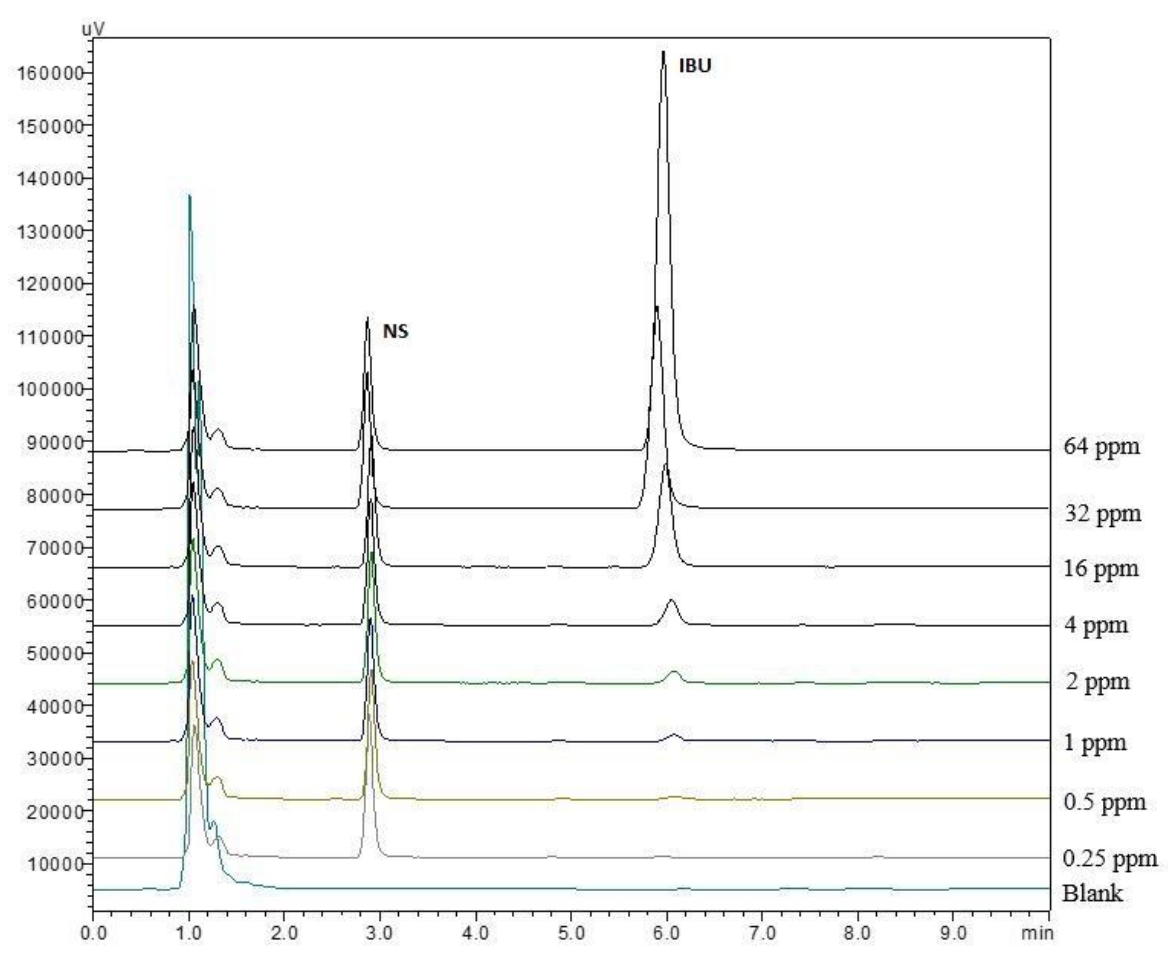

Figure 3. Chromatograms of calibration samples $\left(0.25-64.0 \mu \mathrm{g} \mathrm{mL} \mathrm{mL}^{-1} \mathrm{IBU}\right)$. Experimental conditions: mobile phase: acetonitrile: potassium phosphate buffer $(\mathrm{pH} 3.0,15 \mathrm{mM})(56: 44 \mathrm{v} / \mathrm{v})$, flow rate: $1 \mathrm{~mL} \mathrm{~min}^{-1}$; injection volume: $20 \mathrm{~mL}$, detection wavelength: $220 \mathrm{~nm}, \mathrm{NS}: 2.5 \mu \mathrm{g} \mathrm{mL} \mathrm{m}^{-1}$

\subsection{Method validation}

\subsubsection{Linearity and sensitivity of the developed method}

The linearity of the analysis is a measure of the acquis ition of test results directly proportional tothe analyte concentration in the sample [19]. The calibration curve was constructed between 0.25 and $64.0 \mu \mathrm{g} \mathrm{mL}^{-1}$ where the method was linear. Sensitivity values of the developed method were calculated from the following equations.[24].

The linearity and sensitivity findings of the establishe $\mathrm{d}$ technique are summarized in Table 2.

LOQ (Limit of Quantification) and LOD (Limit of Detection) values of PCA were calculated due to the following equations (Table 4).

$\mathrm{LOD}=(3.3 \mathrm{x}$ standard deviation of the response $) /$ slope of the calibration curve $\mathrm{LOQ}=(10 \mathrm{x}$ standard deviation of the response $) /$ slope of the calibration curve

Table 2. Linearity and sensitivity of the developed method $(n=6)$

\begin{tabular}{ll}
\hline Regression equation & $\mathrm{y}=0.0851 \mathrm{x}+0.0125$ \\
Standard error of intercept & 0.0393 \\
Standard error of slope & 0.0204 \\
Regression coefficient $\left(\mathrm{R}^{2}\right)$ & 0.9993 \\
Range $(\mu \mathrm{g} \mathrm{mL}-1)$ & $0.25-64$ \\
Number of data points & 8 \\
LOD $\left(\mu \mathrm{g} \mathrm{mL}^{-1}\right)^{*}$ & 0.15 \\
LOQ $\left(\mu \mathrm{g} \mathrm{mL}^{-1}\right)^{*}$ & 0.25 \\
\hline
\end{tabular}

* LOQ: Limit of quantification, LOD: Limit of detection 


\subsubsection{Trueness and precision of the developed method}

Three different IBU concentrations in the linear range were analyzed on three consecutive days (inter-day studies) and three times on the same day (intra-studies) (Table 3). Dublicate injections were performed. Trueness of the method is explained by the relative error (RE) values, while precision was stated with relative standard deviation values (RSD). The RE values in the intra-day and inter-day studies were between 3.61 and 6.07 , respectively. The relative standard deviations of the intra-day and inter-day studies were between 2.54 and 9.98, respectively. The findings showed that the analysis method developed was accurate and precise $(\mathrm{RSD}<15 \%)$

Table 3. Precision and trueness of the proposed method $(n=6)$

\begin{tabular}{lllllll}
\hline & Intra- day & & \multicolumn{1}{l}{ Inter- day } \\
\hline $\begin{array}{c}\text { Added } \\
\left(\mu \mathrm{g} \mathrm{mL}^{-1}\right)\end{array}$ & $\begin{array}{c}\text { Found } \\
\left(\mu \mathrm{g} \mathrm{mL}^{-1}\right)\end{array}$ & $\begin{array}{c}\text { Precision } \\
(\mathrm{RSD} \%)\end{array}$ & $\begin{array}{c}\text { Trueness } \\
(\text { Bias \% })\end{array}$ & $\begin{array}{c}\text { Found } \\
\left(\mu \mathrm{g} \mathrm{mL}^{-1}\right)\end{array}$ & $\begin{array}{c}\text { Precision } \\
(\mathrm{RSD} \%)\end{array}$ & $\begin{array}{c}\text { Trueness } \\
(\text { Bias \% })\end{array}$ \\
\hline 4.00 & $3.87 \pm 0.210$ & 6.83 & -3.07 & $4.08 \pm 0.13$ & 2.54 & 2.05 \\
16.00 & $15.84 \pm 0.353$ & 4.72 & -0.99 & $16.97 \pm 0.31$ & 3.39 & 6.07 \\
64.00 & $64.08 \pm 0.572$ & 3.07 & 0.13 & $64.30 \pm 0.58$ & 3.10 & 0.47 \\
\hline
\end{tabular}

Found: Mean \pm standard error ( $\bar{X} \pm S E$ ), RSD \% Relative standard deviation, Bias \%: [(Found-Added)/Added] x 100

\subsubsection{Selectivity of the developed method}

The selectivity of the analysis is the ability of to the system to recognize a specific compound within the analyzed matrices. Therefore, the blank, plasma-spiked IBU and standard IBU chromatograms were compared. (Figure 4). IBU and NS were separated at retention times of 5.90 and 2.81 minutes, respectively without any interference from matrix components.

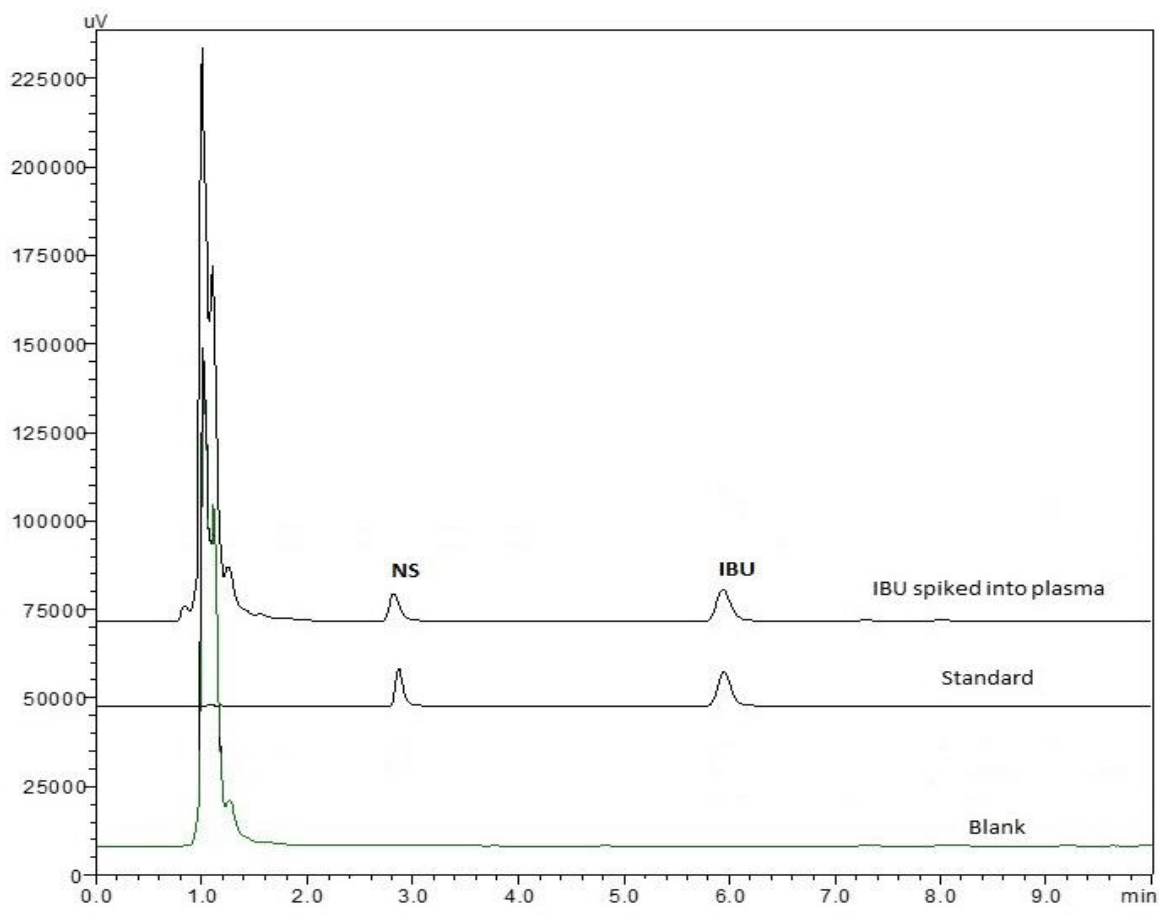

Figure 4. Chromatograms of blank plasma sample, standard sample and spiked in plasma under indicated experimental conditions (IBU:20 $\mu \mathrm{g} \mathrm{mL}^{-1}$ and $\mathrm{NS}: 2.5 \mu \mathrm{g} \mathrm{mL}^{-1}$ ) 


\subsubsection{Recovery of the developed method}

For $4.0,16.0$ and $64.0 \mu \mathrm{g} \mathrm{mL}^{-1}$ concentrations of plasma samples, as defined in the experimental section, the recovery of the established analytical method was investigated. The developed method was applied to three different concentration levels in the linearity range for six times. For IBU, the recoveries from plasma samples of $4.0,16.0$ and $64.0 \mu \mathrm{g} / \mathrm{mL}$ in concentration, respectively, were $100.05 \%$ (SD: 0.10 ), $102.01 \%$ (SD: 0.57) and 100.19\% (SD: 2.00) (SD: Standard deviation, $\mathrm{n}=6$ ). The results show that the developed method for IBU analysis using ultrafiltration-based extraction sample preparation step from human plasma samples is accurate.

\subsubsection{Robustness}

The effects of small and deliberate changes in the chromatographic conditions of the analysis from optimized conditions were tested with the robustness test. The changed parameters were flow rate, buffer concentration and acetonitrile ratio of the mobile phase (Table 4). Due to robustness tests for synthetic tablet analysis $20 \mu \mathrm{g} / \mathrm{mL}$ of IBU were calculated from found concentrations and it was examined that there was no difference statistically proven between them ( $p>0.05)$.

Table 4. Results of robustness findings (IBU: $10 \mu \mathrm{g} \mathrm{mL}^{-1}$, NS: $10 \mu \mathrm{g} \mathrm{mL}^{-1}, \mathrm{n}=3$ )

\begin{tabular}{lccc}
\hline Parameters & Found & RSD \% & t calculated \\
\hline Optimum conditions & $19.06 \pm 0.06$ & 0.52 & - \\
Flow rate $0.95 \mathrm{~mL} \mathrm{~min}^{-1}$ & $19.05 \pm 0.04$ & 0.33 & 0.72 \\
Flow rate $1.05 \mathrm{~mL} \mathrm{~min}^{-1}$ & $19.10 \pm 0.01$ & 0.13 & 0.59 \\
Buffer concentration $13 \mathrm{mM}$ & $18.78 \pm 0.05$ & 0.43 & 0.04 \\
Buffer concentration $16 \mathrm{mM}$ & $18.93 \pm 0.02$ & 0.17 & 0.16 \\
Acetonitrile ratio 54\% & $19.40 \pm 0.04$ & 0.38 & 0.02 \\
Acetonitrile ratio 58\% & $19.28 \pm 0.07$ & 0.61 & 0.11
\end{tabular}

The results were compared with the results obtained under optimum conditions ( $p>0.05$, $\mathrm{t}_{\text {table: }}$ 4.30)

\subsection{Analysis of spiked plasma samples}

The results from the analysis of $20.0 \mu \mathrm{g} \mathrm{mL}^{-1} \mathrm{IBU}$ spiked plasma samples with the developed HPLC method were evaluated using the regression equation from the calibration curve. The results (Table 5) proposed that ultrafiltration-based extraction can be successfully used for IBU analysis in human plasma samples with the developed HPLC method. It should be noted that the proposed extraction technique dilutes the sample concentration up to $5 x$, so the plasma concentration of the analyzed compound should be below the linear range.

Table 5. Determination of IBU from spiked plasma samples

\begin{tabular}{ll}
\hline Added amount $\left(\mu \mathrm{g} \mathrm{mL}^{-1}\right)$ & Found amount $\left(\mu \mathrm{g} \mathrm{mL}^{-1}\right)$ \\
\hline & 19.41 \\
& 19.30 \\
20.00 & 19.48 \\
& 19.12 \\
& 19.33 \\
& 19.40 \\
$\overline{\mathbf{X}}$ & $19.34 \pm 0.14$ \\
SD & 0.12 \\
RSD $(\%)$ & 0.64 \\
\hline
\end{tabular}

$\overline{\mathrm{X}}:$ Mean \pm Standard error; SD: Standard Deviation; RSD: Relative Standard Deviation

\subsection{Advantages and disadvantages of Ultrafiltration-Based extraction}

The results of this study show that ultrafiltration-based extraction can be successfully applied to determine IBU from human plasma samples. The application of ultrafiltration-based extraction can be an effective alternative. However, the costs of the filters used in this technique should be considered for high sample amounts. In our analysis, we injected more than one hundred and twenty samples altogether and the column backpressure was stable around 102 bar. This can be stated that interference in the supernatant after protein precipitation can damage the next generation HPLC columns after several dozen injections. Column life can be an extra cost for analysis when protein precipitation alone is used. The ultrafiltration-based extraction proposed in this study not only preserves column life, but also prevents peaks from parasites in the matrix components. Solid phase extraction also requires commercial filters and can be used in pharmaceutical analysis. The advantage of ultrafiltration versus solid phase extraction is that it is simpler to apply and does not require additional buffers to be prepared. In addition, depending on the capacity of the centrifuge, more than a hundred samples can be prepared in the same order, which is almost impossible for solid phase extraction or takes too long and effort compared to ultrafiltration-based extraction. Liquid- 
liquid extraction is another way to analyze drugs from human plasma samples. The problem for liquid-liquid extraction is that water-soluble pharmaceuticals are difficult to separate from plasma samples with organic solvents, or the recoveries are relatively low and require some extra procedures. In this case, the method presented in this study can be modified to identify water- and fat-soluble active pharmaceutical ingredients, including NSAIDs, in human plasma samples in further studies.

\section{Conclusion}

One of the main components of pharmaceutical science is pharmaceutical analysis. Studies such as pharmaceutical quality control, dissolution tests, pharmacokinetic studies and drug interaction studies are also based on analytical analysis. Because of its simplicity behind its precision, HPLC is still one of the most flexible techniques compared to electrochemistry, capillary electrophoresis and UVSpectroscopy. Although LC-MS / MS is a valuable technique for pharmacokinetic studies with better sensitivity and selectivity advantages, HPLC equipped with UV detector is a simple, fast and cost-effective alternative. However, the HPLC-UV technique cannot be directly adapted to pharmacokinetic studies as it requires pre-cleaning procedures to prevent unwanted interference from matrix components as a result of plasma samples. For biological samples, commercial solid-phase extraction and liquid-liquid extraction equipments offer valuable alternatives to pre-cleaning procedures.

At this point, the reason why extraction based on ultrafiltration is seldom used in pharmaceutical research. In the study presented, IBU was extracted via commercial centrifugal filters from plasma samples and satisfactory results were observed. A large variety of active pharmaceutical ingredients can be adapted to the methodology proposed in this study.

\section{Conflicts of interest}

The authors state that they did not have any conflict of interests

\section{References}

[1] Crofford L.J., Use of NSAIDs in Treating Patients with Arthritis, Arthritis Res. Ther., 15 (S3) (2013) $\mathrm{S} 2$.

[2] Simon L.S., Nonsteroidal Anti-inflammatory Drugs and Their Risk: A Story Still in Development, Arthritis Res. Ther., 15 (S3) (2013) S1.
[3] Cha Y.I., DuBois R.N., NSAIDs and Cancer Prevention: Targets Downstream of COX-2, Annu. Rev. Med., 58 (2007) 239-252.

[4] Tinsley H.N., Grizzle W.E., Abadi A., Keeton A., Zhu B., Xi Y., Piazza G.A., New NSAID Targets and Derivatives for Colorectal Cancer Chemoprevention, Recent Results Cancer Res., 191 (2013), 105-120.

[5] Wang D., DuBois R.N., The Role of Antiinflammatory Drugs in Colorectal Cancer, Annu. Rev. of Med., 64 (2013) 131-144.

[6] Gurpinar E., Grizzle W.E., Piazza G.A., NSAIDs Inhibit Tumorigenesis, But How?, Clin. Cancer Res., 20(5) (2014) 1104-1113.

[7] Tsioulias G.J., Go M.F., Rigas B., NSAIDs and Colorectal Cancer Control: Promise and Challenges, Curr. Pharmacol. Rep., 1(5) (2015) 295-301.

[8] Stambaugh Jr J.E., Drew J., The Combination of Ibuprofen and Oxycodone/Acetaminophen in the Management of Chronic Cancer Pain, Clin. Pharmacol. Ther., 44(6) (1988) 665-669.

[9] Portenoy, R.K., Lesage P., Management of cancer pain, Lancet, 353(9165) (1999) 1695-1700.

[10] Derry S., Wiffen P.J., Moore R., McNicol E.D., Bell R.F., Carr D.B., McIntyre M., Wee B., Oral Nonsteroidal Anti-Inflammatory Drugs (Nsaids) for Cancer Pain in Adults, Cochrane Database of Syst. Rev., 7 (2017)

[11] Carr D.B., Goudas L.C., Balk E.M., Bloch R., Ioannidis J.P., Lau J., Evidence Report on the Treatment of Pain in Cancer Patients, J. Natl. Cancer Inst. Monogr., 32 (2004) 23-31.

[12] Abdulla A., Adams N., Bone M., Elliott A.M., Gaffin J., Jones D., Knaggs R., Martin D., Sampson L., Schofield P., British Geriatric Society, Guidance on the Management of Pain in Older People, Age Ageing, 42 (S1) (2013) 1-57.

[13] Kamsvåg, T., Hedén L., Essen L. V. Ljungman G., Ibuprofen in Needle Procedures in Children with Cancer-A Feasibility and Pilot study, Acta Paediatr., 110 (2) (2020) 704-710.

[14] Rainsford, K., Ibuprofen: Pharmacology, Efficacy and Safety, Inflammopharmacology, 17(6) (2009) 275-342.

[15] Leising G., Resel R., Stelzer F., Tasch S., Lanziner A., Hantich G., Physical Aspects of Dexibuprofen and Racemic Ibuprofen, J. Clin. Pharmacol., 36(12) (1996) 3S-6S. 
[16] Davies N.M., Clinical Pharmacokinetics of Ibuprofen, Clin. Pharmacokinet, 34(2) (1998) 101-154.

[17] Locatelli M., Tartaglia A., D'Ambrosio F., Ramundo P., Ulusoy H.I., Furton K.G., Kabir A., Biofluid Sampler: A New Gateway for Mail-inAnalysis of Whole Blood Samples, $J$. Chromatogr. B., 1143 (2020) 122055.

[18] D'Angelo V., Tessari F., Bellagamba G., De Luca E., Cifelli R., Celia C., Primavera R., Di Francesco M., Paolino D., Di Marzio L., Locatelli M., Microextraction by Packed Sorbent and HPLC-PDA Quantification of Multiple AntiInflammatory Drugs and Fluoroquinolones in Human Plasma and Urine, J. Enzyme Inhib. Med. Chem., 31(Sup3) (2016) 110-116.

[19] Çelebier M., Nenni M., Altınöz S., UltrafiltrationBased Extraction and HPLC Analysis of Naproxen Sodium in Human Plasma Samples: An Innovative Approach to Pharmaceutical Analysis, Pharm. Chem. J., 50(4) (2016) 275-279.

[20] FDA, Guidance for Industry: Bioanalytical Method Validation. 2018.

[21] Tartaglia A., Kabir A., D'Ambrosio F., Ramundo P., Ulusoy S., Ulusoy H.I., Merone G.M., Savini F., D'Ovidio C., Grazia U., Furton K.G., Locatelli M., Fast Off-line FPSE-HPLC-PDA Determination of Six NSAIDs in Saliva Samples, J. Chromatogr. B., 1144 (2020) 122082.

[22] Locatelli M., Tartaglia A., Ulusoy H. I., Ulusoy S., Savini F., Rossi S., Santavenere F., Merone G. M., Bassotti E., D’Ovidio C., Rosato E., Furton K. G., Kabir A., Fabric-Phase Sorptive Membrane Array As a Noninvasive In Vivo Sampling Device For Human Exposure To Different Compounds, Anal. Chem., 93(4) (2021) 1957-1961.

[23] Karaca E., Ulusoy S, Morgül Ü., Ulusoy H., Development of Analytical Method for Sensitive Determination of Streptozotocin Based on Solid Phase Extraction, Cumhuriyet Sci. J., 41(4) (2020) 826-831.

[24] Bonfilio R., Cazedey E. C. L., de Araújo M. B., Salgado H. R. N., Analytical Validation of Quantitative High-Performance Liquid Chromatographic Methods in Pharmaceutical Analysis: A Practical Approach, Crit. Rev. Anal. Chem., 42 (1) (2012) 87-100. 